\title{
Vivências de pessoas com diabetes e amputação de membros
}

\author{
Experiences of people with diabetes and amputation of members \\ Vivencias de personas con diabetes y amputación de miembros
}

\author{
Nancy Nay Leite de Araújo Loiola Batista', Maria Helena Barros de Araújo Luz" \\ ' Prefeitura Municipal de Teresina, Programa de Saúde da Família. Teresina-PI, Brasil. \\ "Universidade Federal do Piauí, Curso de Enfermagem. Teresina-Pl, Brasil.
}

Submissão: 16-10-2010 Aprovação: 12-07-2012

\begin{abstract}
RESUMO
Trata-se de um estudo exploratório, descritivo, com abordagem qualitativa, na perspectiva fenomenológica heideggeriana. Foi desenvolvido no Centro Integrado de Saúde Dr. Lineu Araújo e em Unidades Básicas de Saúde, de Teresina (PI), tendo como sujeitos doze pacientes diabéticos e amputados. Utilizou-se como técnica para produção dos dados a entrevista fenomenológica. Na tentativa de aproximação e apropriação dos significados por eles atribuídos, foram construídas quatro Unidades de Significação. Nesta perspectiva, Ser-pessoa-com-diabetes-e-amputações de membros significa vivenciar um cotidiano permeado por dificuldades, limitações e restrições impostas pela situação; sofrer pela dependência de outras pessoas, pela solidão imposta pelo isolamento social, seja por limitações pessoais, econômicas e/ou inadequação das políticas públicas.
\end{abstract}

Descritores: Enfermagem; Diabetes mellitus; Amputação.

\begin{abstract}
This is an exploratory, descriptive, qualitative study, built up on Heidegger's phenomenological perspective. It was developed at the Integrated Health Center Dr. Lineu Araújo and at Basic Health Units of Teresina (PI), with the subjects being twelve diabetic patients that have suffered member's amputation. Phenomenological interview was used, as the technique for producing the data. In an attempt of approaching and appropriation of the meanings they attributed to the phenomena, four units of meaning were built. In this perspective, being-person-with diabetes-and-member amputations means experiencing a quotidian permeated by difficulties, restrictions and limitations imposed by the situation; suffering for dependence on others, loneliness imposed by social isolation, either by personal limitations, economic and / or inadequacy of public policies.
\end{abstract}

Key words: Nursing; Diabetes mellitus; Amputation.

\section{RESUMEN}

Este es un estudio exploratorio, descriptivo, con enfoque cualitativo, desenvuelto en la perspectiva fenomenológica heideggeriana. Se desarrolló en el Centro Integrado de Salud Dr. Lineu Araújo y en una Unidad Básica de Salud de Teresina (PI), teniendo como sujetos doce pacientes diabéticos sometidos a amputaciones. Como técnica para producir los datos, se utilizó la entrevista fenomenológica. En un intento de acercamiento y apropiación de los significados que ellos atribuyen al fenómeno, se construyeron cuatro unidades de significado. En consecuencia, Ser persona-con diabetes-y- amputación de miembros significa experimentar un cotidiano impregnado por dificultades, restricciones y limitaciones impuestas por la situación; y sufrir por la dependencia de otros, y de la soledad impuesta por el aislamiento social, ya sea por limitaciones personales, económicas y / o por insuficiencia de políticas públicas.

Palabras clave: Enfermería; Diabetes mellitus; Amputación. 


\section{INTRODUÇÃO}

Viver com diabetes pode representar um desafio tanto para a pessoa quanto para aqueles que estão próximos a ela, pois a condição de estar diabético e amputado afeta a vida como um todo, alterando drasticamente o cotidiano, exigindo uma vivência de comportamentos especiais, de autocuidado para que a glicemia seja mantida o mais próximo possível de suas possibilidades e potencialidades, pois o controle inadequado da doença ao longo dos anos representa grave ameaça à vida do portador.

É relevante pontuar que, o Diabetes Mellitus (DM) atinge em todo mundo, um grande número de pessoas de qualquer idade e condição social. A doença acarreta mudanças significativas na relação que o paciente diabético estabelece com seu próprio corpo, com as outras pessoas e com o mundo que o cerca. As dificuldades apresentadas pelos pacientes para obtenção de um bom controle metabólico estão relacionadas à sua adesão a um plano alimentar, ao incremento de atividade física e ao segmento da terapêutica medicamentosa ${ }^{(1)}$.

Estudos a respeito do enfrentamento da doença crônica referem-se ao impacto que a progressiva degeneração tem para o indivíduo, a família e a comunidade, pois ocasiona inevitavelmente problemas relacionados ao isolamento social, empobrecimento da autoimagem, conflitos gerados pela dependência, pressão econômica e a possibilidade de morte ${ }^{(2-5)}$. E, quando surgem as complicações como lesões e úlceras nos pés, o medo de uma amputação gera mais preocupação aos diabéticos, pois é fato conhecido, até por pessoas leigas no assunto, a possibilidade de perda de partes do corpo como conseqüência do DM.

Estudos internacionais citados por Gamba ${ }^{(6)}$ apontam que portadores de DM têm quinze vezes mais chances de vir a sofrer uma amputação do membro inferior do que os que não têm a doença. O DM é responsável por metade das amputações não traumáticas no mundo. Estima-se que, em nível global, a prevalência do DM seja em torno de 120 milhões de indivíduos e que de 4 a $10 \%$ destes desenvolvem lesões nos pés, portanto não é infundada a preocupação e o medo dos pacientes ${ }^{(7)}$.

Estudos sobre a qualidade de vida de diabéticos amputados divergem, mostrando que a qualidade de vida apresenta-se reduzida em diabéticos com amputações, principalmente nos pacientes com amputações maiores, representando um grande desafio a ser superado ${ }^{(8)}$. Sua ocorrência causa sérias mudanças no campo estético, na autoestima, na mobilidade, na capacidade de realizar atividades da vida diária, no trabalho e no lazer ${ }^{(14)}$. Pessoas incapacitadas podem ter boa qualidade de vida quando ultrapassam limites e conseguem equilíbrio entre mente, corpo e espírito ${ }^{(9)}$.

Perder uma parte do corpo é ter alterada toda uma existência, é viver uma incompletude que traz consigo uma série de alterações no existir. É ter que se adaptar, readaptar, aprender a viver novamente, agora assumindo outra perspectiva no mundo para si e para os outros ${ }^{(10)}$.

Ao se considerar o DM uma condição crônica de saúde, a redução das complicações como a amputação só será possível se ele participar ativamente do tratamento. Para isso, é preciso resgatar as experiências, o conhecimento, os sistemas de valores e crenças que orientam as atitudes desses pacientes em relação a sua própria saúde.

Ao eleger como objeto deste estudo as "Vivências de pessoas com diabetes e amputações de membros", pretendemos compreender o ser humano com diabetes e amputações de membros com base nos significados por ele atribuídos à sua vivência, que orientam e dão sentido às suas ações. Por se tratar de um objeto de estudo que tem por base a subjetividade do sujeito, naquilo que emana dele, o referencial de sustentação ao estudo, portanto, foi a fenomenologia. É, pois, uma proposta teórico-filosófica que utiliza os conceitos de Martim Heidegger ${ }^{(11)}$ para interpretação dos conteúdos dos discursos dos sujeitos.

Nessa compreensão, Heidegger ${ }^{(11)}$ nos ajuda a esclarecer o objeto como um caminho a ser desvelado pela fenomenologia quando coloca que o homem atribui significado às coisas com as quais se relaciona no horizonte de sua existência. E o expõe aos entes ao seu redor através de sua linguagem.

Como busco compreender os diabéticos amputados na sua facticidade, aproximo-me da fenomenologia já que a pesquisa fenomenológica permite desvelar sentimentos e emoções, revelar o que se encontra velado, escondido no Ser, busca o que é essencial, o que é invariante para que se possa chegar à essência do fenômeno. Deixar e fazer ver por si mesmo aquilo que se mostra, tal como se mostra a partir de si mesmo ${ }^{(11)}$.

Mediante esse objeto do estudo, foram elaboradas as seguintes questões norteadoras: $O$ que significa ser diabético amputado? Como o diabético amputado vivencia seu cotidiano? Para responder a tais questionamentos pontuamos, como objetivo, o de compreender as vivências dos diabéticos amputados a partir dos significados por eles atribuídos.

Cumpre referir que o estudo pretende contribuir para uma reflexão sobre a problemática da vivência da pessoa diabética, especialmente daquelas submetidas a amputações de membros, para a busca incessante de um cuidar fundamentado no indivíduo como um ser único, que precisa ser visto na sua totalidade, integrado a um contexto familiar e social. Pretende também contribuir como subsídio para o conhecimento e a prática dos profissionais de saúde, particularmente os enfermeiros, envolvidos na assistência a essa clientela.

\section{METODOLOGIA}

Trata-se de um estudo exploratório, descritivo com abordagem qualitativa na perspectiva fenomenológica heideggeriana. O método fenomenológico em Heidegger conduz a uma reflexão e análise interpretativa denominada de hermenêutica heideggeriana, que leva à produção de um conhecimento compatível com uma ciência de rigor, por sua radicalidade, originariedade e originalidade, que não tem a pretensão de oferecer respostas prontas, acabadas, mas sim despertar para uma melhor compreensão do ser humano em sua existencialidade como um ser único e irrepetível ${ }^{(19)}$.

O estudo foi desenvolvido no Centro Integrado de Saúde Dr. Lineu Araújo (CISLA) e em Unidades Básicas de Saúde da FMS de Teresina-PI. Os sujeitos compreenderam 10 pessoas com diabetes e amputações de membros que moram em Teresina e que tem pelo menos um ano de amputação. 
A produção dos dados foi realizada no período de 16 de abril a 20 de maio de 2008, utilizando como técnica para obtenção dos depoimentos a entrevista fenomenológica, com duração média de meia hora. Seguindo a orientação fenomenológica, as entrevistas foram realizadas em local adequado, em cômodos da casa que ofereciam condições satisfatórias de privacidade, tranqüilidade e que permitiram a ambos, pesquisador e pesquisado se sentirem à vontade. Então eram apresentados e esclarecidos os propósitos e objetivos da pesquisa, e lido em conjunto o Termo de Consentimento Livre e Esclarecido.

Pudemos compreender a intersubjetividade da pesquisa fenomenológica, que é a própria relação entre pesquisador e pesquisado. Os encontros com os depoentes foram marcados pela intensa relação interpessoal, mediado pela empatia em que deixamos de ser entes simplesmente dados para sermos presença.

O roteiro para a entrevista foi validado antes de ser aplicado aos sujeitos do estudo. No início de cada entrevista, perguntávamos aos entrevistados se gostariam de escolher o nome de um bichinho de estimação ou o de uma flor, para proteger a sua identidade no estudo. Sete depoentes aceitaram e apenas três preferiram ser identificados pelos seus próprios apelidos.

Após a realização das entrevistas, elas foram transcritas na íntegra e destacados os núcleos essenciais, que emergiram de suas falas, para construção das unidades de significação. $\mathrm{O}$ estudo foi submetido à apreciação do Comitê de Ética em Pesquisa (CEP) da Universidade Federal do Piauí e da Fundação Municipal de Saúde de Teresina, capital do estado do Piauí e obteve aprovação conforme Parecer $n^{\circ} .37 / 08$.

\section{RESULTADOS E DISCUSSÃO}

A partir da transcrição, leitura e releitura das falas dos depoentes busquei identificar as estruturas invariantes, que se repetiam nos discursos das vivências do ente diabético com amputações de membros, tentando aproximar-me e me apropriar dos significados por eles atribuídos, possibilitando a construção de quatro unidades de significação.

Ser-diabético amputado significa: vivenciar um cotidiano permeado por dificuldades, limitações e restrições

Nesta primeira unidade de significação sobre o significado de ser diabético e amputado a maioria dos entrevistados refere um cotidiano alterado pela amputação e mostram as dificuldades, limitações e restrições, as quais podem ser evidenciadas nas falas dos seguintes depoentes:

É ruim, porque eu não posso andar, não posso ir pra canto nenhum, é ruim minha gente [...] para levantar a filha me levanta, me "banha" [...]. Eu gostava de viajar, de ir pra festa, pra tudo, de carnaval, as minhas amigas vão e eu não posso. As minhas amigas de farra não vêm me visitar, quando vêm estou dormindo. Hoje não posso viajar (Maria).

Hoje é muito difícil para mim porque nem caminhar eu posso, nem dirigir eu dirijo [...]. Mas então o que eu gostava é isso, caminhar, passear, ir pro shopping. Hoje eu não posso mais fazer isso, eu não vou sair de cadeira de rodas "prum" shopping alguém empurrando (Bem-te-vi.).

Agora a gente acha que as pessoas tem pena da gente, tão olhando de uma outra forma, por isso eu não gosto de sair, acho que tem pena da gente, sei lá, acho diferente [...]. Passei um ano com depressão. (Florzinha).

Não boto nem comida no prato pra mim, nem um café, se eu for botar assim uma coisa pra eu comer, eu derramo [...]. Eu passo o dia assim, aqui sentado (Peixinho).

Porque uma pessoa também que tem prótese tem dificuldade de se locomover, os ônibus são altos, os motoristas não têm muita paciência com as pessoas deficientes (Pássaro).

Todas as falas apresentadas nessa unidade de significação permitiram perceber o que foi modificado no cotidiano dos diabéticos com a amputação. Surge o isolamento social e familiar referido por Maria, Bem-te-vi, Florzinha, Pássaro e o sofrimento provocado pela dependência dos outros em Maria e Flor, pela não aceitação de si, na fala de Florzinha, da solidão, em Maria e das dificuldades para realizar atividades, que antes faziam com autonomia, independência e tranqüilidade, relatadas por Maria, Bem-te-vi, Florzinha, Peixinho e Pássaro.

Essas modificações no cotidiano são de grande dimensão, impactantes e significam uma vivência difícil para o ser diabético amputado quando revelam sofrimento provocado pela dependência, pelo isolamento social que é fruto da dependência da acessibilidade e de outros fatores. Mostram solidão, gostariam de participar ativamente da vida social, familiar e comunitária. A amputação traz acima de tudo a limitação e, com ela, a acomodação.

Heidegger ${ }^{(11)}$ chama de facticidade o fato do homem, na sua existencialidade, ter sido lançado no mundo independente de sua vontade, e sua existência o impõe a situações não planejadas, não desejadas e esperadas por ele. Mundo para Heidegger não é só o espaço físico onde se vive, mas é o contexto em que a pré-sença vive; o mundo circundante é o círculo de interesses, preocupações, desejos, ideais, afetos, conhecimentos, conjunto de condições socioeconômicas. É neste mundo que o homem está imerso, situado e é um mundo de possibilidades. Ninguém escolhe ser-diabético nem amputado, dentre essas possibilidades ele ficou diabético e foi amputado.

Heidegger ${ }^{(11)}$ fala que um sujeito não é e nunca é dado sem mundo, não é dado um eu isolado sem os outros. Os outros já estão co-presentes no Ser-no- mundo, possibilitando assim a compreensão do sofrimento provocado pela solidão devido a amputação.

\section{Ser-diabético e amputado significa não aceitar a doença e não seguir o tratamento}

A possibilidade ser-diabético com todas as suas limitações e restrições foi lançada aos sujeitos do estudo como algo inesperado obrigando um redimensionamento do cotidiano. 
Passa a fazer parte do dia a dia da pessoa com diabetes a convivência com dieta; uso de medicamentos orais ou injetáveis que devem ser tomados de forma sistemática; uma série de recomendações e comportamentos especiais; novos vocabulários como glicemia e hipoglicemia; visitas regulares aos centros de saúde; consultas com médicos e enfermeiros; retirada de sangue para realização de exames.

Com a amputação surge mais alteração no cotidiano, com mais limitações e novas vivências. Essas pessoas se vêem de repente, com uma nova possibilidade, de ser-diabético com amputações, tendo que se adequar e viver com todas essas informações e obrigações. Aparecem sentimentos de não aceitação da doença, de rejeição ao tratamento, ao uso da insulina, e de transgressão a dieta.

Não gosto de ser diabética. Só Deus mesmo. Foi difícil aceitar quando o médico cortou a perna, eu não queria não [...] Eu não gosto da dieta, não gosto de nada que posso comer, uso o adoçante, não gosto da dieta que o médico passa, só quero comer comida normal (O Louro).

Eu nunca me aceitei, eu não faço é me aceitar mesmo. Já fui a psicólogo, seis meses, paguei consulta para a mulher me acompanhar, que eu tava quase louca, me deu uma depressão, por que eu não aceitava, chorava muito, por que logo comigo, é muito ruim mesmo (Florzinha).

[...] estou me preparando para ir ao doutor, eu vou pedir pra ele para comer macarrão com sardinha, pra ver se pelo menos uma vez por mês ele me libera. [...] a filha vai ficar com muita raiva, mas eu não vou dizer pra ela que eu vou perguntar isso (Meu amorzinho).

Às vezes eu sou danada pra transpassar no doce. Aí agora deu um problema nos meus rins "né", que a médica disse que é através da diabete, aí a médica proibiu de triscar em açúcar, nem por brincadeira, aí agora eu já eliminei, não como nada, tenho vontade e não me iludo (Flor).

Eu prefiro morrer que comer a comida da dieta (Maria).

Em relação ao seguimento da dieta, percebe-se que todos os depoentes apresentam dificuldade em cumpri-la, em todos os momentos do cotidiano como descrito por Meu amorzinho, Florzinha, Flor, Maria, e o Louro. Alguns até referem só comer o que o médico prescreve: verduras e frutas, como Meu amorzinho, Florzinha e Flor. No entanto, mais adiante deixam revelar de forma indireta que comem algo que não é permitido e que sabem o que têm que fazer quando sentem alguma coisa, que indica que a taxa de açúcar está alta, pelo que foi transgredido, como observa Florzinha. O único depoente que não deixou revelar em sua fala que transgride a dieta foi Pássaro, que, no momento da entrevista, pediu a sua mulher que fosse comprar um lanche na padaria e a mesma trouxe um refrigerante zero e um bolo doce de chocolate que ele comeu naturalmente, demonstrando ser um hábito comum em seu cotidiano, pois não foi questionado em momento algum pela sua esposa.

Uma das dificuldades de aceitar a condição de diabéticos foi em relação aos prazeres da alimentação. O mundo circundante é um apelo ao degustar. Tradicionalmente todas as situações possibilitam a concretização desse prazer, como as ocasiões sociais, o comércio e outros eventos, tudo gira em torno da comida, tornando difícil a adaptação às restrições alimentares. Ao surgir uma complicação como a amputação de membros as recomendações dietéticas devem ser seguida a risca, de uma forma mais rigorosa, gerando mais oportunidades de transgressão e sentimentos de não aceitação.

As pessoas ficam presas ao seu cotidiano, não conseguem vislumbrar novas possibilidades de ser. Quando a presença aprisiona-se na sua temporalidade de passado deixando-se guiar pela situação, pelo cuidado com as coisas, cai na existência inautêntica, como Meu amorzinho, Flor, Peixinho.

O Ser não decide, transfere as suas responsabilidades para o outro, fato que pode ser evidenciado na fala de Meu amorzinho e de Flor, quando diz que vai perguntar ao médico se pode comer pelo menos uma vez por mês sua comida preferida, que sua filha vai ficar zangada, que a médica disse que ela não podia "triscar" em açúcar. Os outros, entes mais próximo ou familiares, são quem determinam o que ela pode ou não comer.

Para Heidegger ${ }^{(11)}$ esse ficar preso na temporalidade, deixando-se guiar pela situação, o cuidado com as coisas levam a presença, o ser, se eximir de suas responsabilidades, não decide, não toma iniciativas, ficando presa ao mundo de todos. Tudo já está decidido na vida cotidiana, é só se acomodar e seguir, caindo na existência inautêntica.

Em suas falas os depoentes revelam a decadência e a impropriedade, que para Heidegger ${ }^{(11)}$ é um dos modos de ser da presença no seu cotidiano, segundo o qual, o ser desviando-se do seu projeto essencial que é o de tornar-se a si mesmo. A presença é chamada a apropriar-se de si mesma, mas ela pode viver na impropriedade, não aceitando a situação imposta facticamente como na fala de Florzinha e de Louro. A impropriedade, ou a inautenticidade não quer dizer ser menos e nem tão pouco um grau inferior de ser, ao contrário, pode determinar toda a concreção da presença em suas ocupações, estímulos, interesses e prazeres. Viver assim na medianidade, nessa indiferença cotidiana da presença não é negativo. E não perder esse modo de ser mais próximo deste ente é torná-lo acessível numa caracterização positiva.

\section{Ser-diabético e amputado significa perceber a ameaça constante de vir a apresentar outras complicações}

Após a visibilidade do diabetes mediada pela amputação, como uma doença crônica e devastadora, a pessoa passa a conviver sob o temor constante de ferimentos e medo de uma nova amputação, além da ameaça velada de lesão e complicação de outros órgãos relacionados ao diabetes.

Perigoso você perder vários membros [...]. Problemas relacionado a diabetes, agora tem o problema renal, tô fazendo hemodiálise (Pássaro). 
Mas o mais, eu tenho medo de me cortar, muitas coisas eu evito (Meu amorzinho).

Eu tenho medo de me machucar (Florzinha).

Após analisar as falas, percebe-se um temor da possibilidade de uma nova amputação, evidenciado pela expressão medo nos depoimentos de Meu amorzinho e Florzinha e de forma ainda oculta no de Pássaro. Evidencia-se também no depoimento de Pássaro o sentir-se reduzido a perspectiva da doença, e de uma vida de cuidado.

Heidegger $^{(11)}$ refere que o fenômeno do medo pode ser considerado sobre três perspectivas: o de que se tem medo, o de ter medo e o pelo que se tem medo. $\mathrm{O}$ de que se tem medo, o amedrontador é sempre um ente que vem ao encontro dentro do mundo. Aquilo de que se tem medo contém o caráter de ameaça, possui o modo conjuntural de ser prejudicial. Enquanto ameaça o prejudicial não se acha numa proximidade dominável, ele se aproxima. Nesse aproximar-se o prejudicial se irradia e seus raios apresentam o caráter de ameaça, aproximando-se na proximidade é que é o prejudicial ameaça, pois pode chegar ou não. O prejudicial traz consigo a possibilidade desvelada de ausentar-se e passar ao largo, o que não diminui nem resolve o medo, mas o constitui.

O ter medo libera a ameaça. Tomando por exemplo os sujeitos do estudo, pessoas com diabetes e amputações de membros, não se constata um mau futuro para então se ter medo, não constata primeiro o que se aproxima, mas em seu ser amedrontador já o descobriu previamente. É tendo medo que o medo pode ter claro para si o de que tem medo ${ }^{(11)}$. A pessoa que já experienciou uma amputação descobriu previamente o amedrontador e sente a ameaça permanente de uma nova amputação, que é algo que pode ou não estar próximo. O medo é desvelado da amputação prévia do próprio membro, é o pavor, pois o de que se tem medo, o amedrontador, já é algo conhecido e familiar, que pode ou não vir, que pode estar próximo, mesmo mantendo a distância.

\section{Ser-diabético e amputado significa a possibilidade de uma vida normal}

A princípio não percebi nos depoimentos algo que pudesse ter contribuído para a construção dessa unidade de significação, parecia que todos os entrevistados estavam presos aos seus diagnósticos e à temporalidade. Foi necessário fazer várias leituras e releituras das transcrições das falas dos sujeitos, para que nos discursos conseguisse identificar palavras que permitissem desvelar que os entrevistados encontram estratégias de enfrentamento de suas dificuldades e lançam-se como projeto de possibilidades.

Vez em quando vou ver, assisto um futebol [...]. Saio com minha esposa, vou ao shopping, de vez em quando a gente vai uma festinha, vai dar um passeio na chácara, se diverte, tem os programas de diabéticos nos postos de saúde que tem passeio e a gente sempre participa [...]. Então a vida da gente é assim, mas dá pra você levar uma vida normal, dá pra você ter tranqüilidade (Pássaro).
E pra mim, a pessoa hoje é deficiente, se tiver boa vontade, você faz, você consegue tudo o que você quer (Florzinha).

O homem não é um espectador passivo no mundo, pelo contrário o homem está lançado no mundo e com ele interage não estando preso a nenhuma situação, mas sempre aberto para se tornar algo novo ${ }^{(13)}$. Essa possibilidade de se tornar algo novo, Heidegger ${ }^{(11)}$ chamou de poder-ser.

Damasceno ${ }^{(14)}$ refere que mesmo sendo um ser em situação, neste estudo em questão, sendo diabético e amputado, o Dasein, ou seja, a pré-sença, não está presa, e sim aberta para além do mundo, para o plano ontológico, é transcendência. Ultrapassa a realidade dada e se dirige à possibilidade. Sendo abertura e possibilidade, o Dasein projeta-se para fora de si mesmo, buscando aquilo que ainda não é, mas que poderá ser.

Percebe-se também que alguns depoentes passaram a perceber o mundo com outros sentidos e buscam o desenvolvimento de novas habilidades:

Gosto de televisão, de ouvir uma música. Eu fico aqui de cabeça baixa, não posso olhar, mas fico aqui de cabeça baixa escutando. É ligada direta pra eu escutar (a TV). Gosto de assistir DVD [...]. Gosto de assistir jornal (Peixinho).

Ainda escuto um rádio, eu fico deitada na área ouvindo rádio (O Louro).

Eu me sinto bem quando eu vou fazer um tapete bonito que eu faço coisas lindas que ninguém acredita que eu tenha feito à mão. Quando eu termino aquilo que eu mostro, quê que tu vai fazer? Vou dar pra fulano, vou vender ás vezes eu vendo pra ele mesmo, aí eu sinto prazer (Meu amorzinho).

Esses depoentes falam de algumas substituições que proporcionam as mesmas emoções como a troca da TV pelo rádio. Para quem é cego funciona como novos modos de interação com o mundo. Outros, apesar da cegueira, o ouvir já leva a viajar no mundo do outro, a TV continua sendo um meio de estar-no-mundo, de sentir o mundo, de saber o que se passa no mundo. É mister pontuar que houve quem expressasse a possibilidade de uma vida normal como:

Mas eu tenho uma vida normal, uma vida boa (Meu amorzinho).

Eu acho que é uma pessoa normal. Apesar desse problema eu levo a minha vida em frente não é [...] Eu tenho vida normal (Dedé).

Uma pessoa como eu que tem boa vontade de fazer minhas coisas, eu faço minhas coisas tranqüilo [...] Levo uma vida normal (Florzinha).

Os sujeitos despertaram e absorvem todo manual e instrumentos de que dispõem na cotidianidade para se libertar e buscar formas possíveis de nova vida pontuadas nas falas de Pássaro e Florzinha; percebem o mundo com outros sentidos como 
Peixinho, Zaque e O louro; desenvolvem outras habilidades, bem como Meu amorzinho. Expressam possibilidade de uma vida normal nos discursos de Meu amorzinho, Dedé e Florzinha.

Heidegger ${ }^{(11)}$ diz que o ser e a estrutura do ser acham-se acima de qualquer ente e de toda determinação ôntica possível de um ente, para ele o ser é um transcendens pura e simplesmente, ou seja, a transcendência do ser da presença é por si só privilegiada, pois nela reside a possibilidade e a necessidade de individuação.

Uma vez aberto para tornar-se algo novo, se manifestar sempre mais, o Dasein é transcendência, ultrapassa a realidade dada e se dirige para a possibilidade. Sendo abertura e possibilidade, projeta-se para fora de si mesmo em busca daquilo que ainda não é, mas que pode ser ${ }^{(11)}$.

\section{CONSIDERAÇÕES FINAIS}

Levando-se em consideração as questões levantadas do que é ser diabético e amputado e como é o seu cotidiano e ainda em conformidade com os objetivos deste estudo, com as leituras complementares realizadas buscou-se um aprofundamento não do diabetes e suas complicações, mas do ser com diabetes e amputações de membros a partir das suas vivências no cotidiano.

Nessa compreensão foi que essa investigação buscou seguir a fenomenologia de Heidegger que conduziu a outra forma de olhar, de superar o modo de pensar tecnológico e orienta a buscar as origens genuínas, ou seja, a instância fundante, que possibilita a tudo manifestar-se.

Desse modo, Ser-pessoa-com-diabetes-e-amputações de membros significa vivenciar um cotidiano permeado por dificuldades, limitações e restrições impostas pela situação; sofrer pela dependência de outras pessoas, pela solidão imposta pelo isolamento social; seja por limitações pessoais, econômicas e ou inadequação das políticas públicas.

Significa ainda não aceitar a doença e nem seguir o tratamento manifestado nas falas que referem transgressões as restrições alimentares e medicamentosas; depender dos outros e ter a vida pessoal e profissional modificada pela doença, viver sobre a dependência do medo da perda da integridade física, da ameaça permanente de outras complicações do diabetes e sentir-se reduzido à perspectiva da doença. Porém pode significar, desenvolvimento de outras habilidades e a busca por novas formas de viver a partir da atual realidade de Ser diabético e amputado.

A Fenomenologia possibilitou um olhar crítico, reflexivo sobre a realidade que nos permeia e que pode servir como subsídio para estarmos refletindo sobre a nossa prática de assistência a essa clientela. Percebe-se que a assistência dada ao diabético pelos profissionais da saúde mantém a forma como a ciência o conceituou, como uma entidade fechada reduzindo os seus pensamentos, sentimentos, percepções e comportamento a fatos que não são considerados relevantes, e obscurecendo a questão do ser- diabético.

O diabético é lançado num mundo já constituído, recebe informações de que é portador de uma doença incurável, mas passível de ser controlada desde que sejam efetuadas mudanças no seu cotidiano e que determinadas regras sejam seguidas. É preciso adaptação de rotinas, inclusão de novos hábitos, limites e novas obrigações. Esse contexto o percebe como algo fechado, isolado da experiência humana, esquece que em seu ser fático, a presença é sempre como e o que ela já foi. As experiências passadas que, às vezes agem e influenciam o presente. Esquecemos que as questões de saúde não acontecem de maneira separada dos demais aspectos da vida de uma pessoa e de uma sociedade.

\section{REFERÊNCIAS}

1. Santos ECB. O cuidado sob a ótica do paciente diabético e de seu principal cuidador. Rev. Latinoam Enferm [periódico na internet] 2006 Maio-Jun [acesso em 16 jun 2006];(3):3 Disponível em: < http://www.scielo.br/scielo.php?script = sci arttext\&pid $=$ S0104-11692005000300015\&in.

2. Corbin JM, Strauss AL. Collaboration: couples working together to manage chronic illness. Image. J Sch Nurs 1984;16(4):109-15.

3. Kerson TS, Kerson LA. Understanding chronic illness: the medical and psychosocial dimensions of nine diseases. New York. London: Free Press: Collier Macmillan; 1985.

4. Lubkin IM. Chronic ilness: impact and intervention. 2. ed. Boston: Jones and Bartlett Publishers; 1990.

5. Martins J. Como fazer fenomenologia. In: Centro de Estudo Fenomenológico. Temas fundamentais de fenomenologia. São Paulo: Morais; 1992.
6. Gamba MA. Amputações de extremidades inferiores por diabetes mellitus: estudo caso-controle. Rev Saúde Pública 2004;38(3):399-404.

7. Consenso Internacional Sobre Pé Diabético. International Consensus on the Diabetic Foot, tradutor. Brasília: Secretaria de Estado de Saúde do Distrito Federal; 2001.

8. Tennvall GR, Apelqvist J. Health-related quality of life in patients whith diabetes mellitus and foot ulcers. J Diabet Complicat 2000;14:235-41.

9. Albrecht GL, Devlieger PJ. The disability paradox: highquality of life against all odds. Soc Med 1999;48:977-88.

10. Chini GCO, Boemer MR. A amputação na percepção de quem a vivencia: um estudo sob a ótica fenomenológica. Rev Latinoam Enferm [periódico na internet] 2007 Apr [acesso em $15 \mathrm{dez}$ 2008];(15): 2 Disponível em: <http:// www.scielo.br/scielo.php?script = sci_arttext\&pid = S0104- 
$-11692007000200021 \& \operatorname{lng}=\mathrm{en} \& \mathrm{nrm}=\mathrm{iso}>$. Acesso em: 15 Dez. 2008. doi: 10.1590/S0104-11692007000200021.

11. Heidegger M, Cavalcante MS, tradutora. Ser e tempo. 4. ed. Petrópolis: Vozes; 2006.

12. Luz MHBA. A dimensão cotidiana da pessoa ostomizada: um estudo de enfermagem na abordagem fenomenológica. Rio de Janeiro. Tese [Doutorado em Enfermagem]- Universidade Federal do Rio de Janeiro; 2001.
13. Moreira RVO, Barreto TAE, organizadores. Machado RCC, Andrade TPP. A reconstrução da metafísica através do método fenomenológico. In: Barreto JAE, Moreira RVO. O elefante e os cegos. Fortaleza: Casa de José de Alencar; 1999.

14. Damasceno MMC, Silva LF, Moreira RVO. Contribuição dos estudos fenomenológicos para o cuidado de enfermagem. Rev Bras Enferm 2001;54(3):475-81. 